\title{
Rechtsschutzversicherung für Ärzte
}

\section{Jetzt Schutz beantragen}

\section{Stellen Sie sich vor,...}

... drei Tage nach dem Erwerb eines Occasionsgerätes versagt dieses seinen Dienst.

... bei einem Verkehrsunfall werden Sie verletzt, die gegnerische Partei bestreitet jedoch ihre Schuld.

... ein Krankenversicherer weigert sich, die von Ihnen erbrachte medizinische Leistung gemäss Tarif zu entschädigen.

Selbst ein friedfertiger Mensch kann heutzutage in eine rechtliche Auseinandersetzung geraten. Und nicht immer lässt sich die Frage wer recht hat, so einfach beantworten. Daraus folgen hohe Anwaltshonorare, Gerichtskosten und Forderungen.

Die FMH Insurance Services Rechtsschutzversicherung hilft Ihnen, zu Ihrem Recht zu kommen. Experten und Anwälte stehen Ihnen im Rechtsstreit mit Rat und Tat zur Seite. Weiter übernimmt die Versicherung Anwaltshonorare und Gerichtskosten bis zu einer Summe von CHF 250000.- pro Schadenereignis.

\section{Versicherte Risiken}

Berufsrechtsschutz für selbständig prak- Verkehrsrechtsschutz für alle mit dem Privatrechtsschutz für alle mit dem Vertizierende Ärzte sowie für angestellte Versicherten im gleichen Haushalt leben- sicherten im gleichen Haushalt lebenden Ärzte und Medizinische Praxisassistentin- den Personen sowie die berechtigten Personen. nen in Ausübung ihrer beruflichen Tätig- Lenker der auf den Versicherungsnehmer keit für die versicherte Praxis (inkl. Über- eingelösten Motorfahrzeuge. arztung).
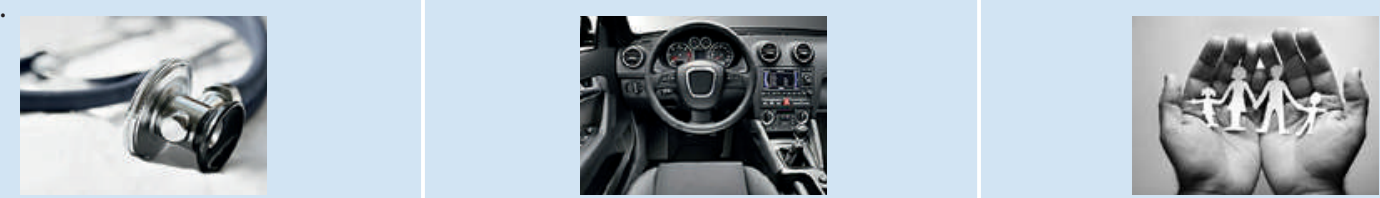

Bestellen Sie die Antragsunterlagen, damit Sie sich und Ihre Familie vor den Folgen eines Rechtsstreites schützen können. Oder rufen Sie uns an, damit wir Sie zu dieser Versicherung oder zu weiteren Themen im Vorsorge-, Vermögens- und Versicherungsbereich beraten können.

\section{Antworttalon}

Bitte einsenden oder per Fax an: 0319595010

Vorname / Name

Adresse

PLZ / Ort

Geburtsdatum

Erwerbsart

Selbständig erwerbend

Angestellt

Telefon Privat / Geschäft

Beste Zeit für einen Anruf

E-Mail-Adresse

O Bitte senden Sie mir Abschlussunterlagen zur FMH Insurance Services Rechtsschutzversicherung.

$\bigcirc$ Ich wünsche eine persönliche Beratung. Bitte rufen Sie mich an.

Ich interessiere mich für:

\begin{tabular}{|c|c|}
\hline Pensionsplanung & Pensionskasse BVG \\
\hline Säule 3a & Krankenkasse \\
\hline Finanz-/Steuerplanung & Berufshaftpflichtversicherung \\
\hline
\end{tabular}

